




\title{
El Arte Latinoamericano en los Estados Unidos durante el siglo XX. Exposiciones, coleccionismo, museología
}

Dra. María Luisa Bellido Gant

Universidad de Granada (España)

mbellido@ugr.es

\section{Resumen}

Este texto reflexiona sobre la presencia del arte latinoamericano en Estados Unidos desde la década de los veinte hasta los años noventa, con el llamado boom del mercado de arte latinoamericano. Nuestro objetivo es presentar de una manera sintética diferentes momentos que jalonaron los vínculos artísticos entre Latinoamérica y Estados Unidos, en especial la presencia, en este país, de artistas de aquella región. Analizaremos las exposiciones individuales y colectivas, el coleccionismo público y privado, la acción institucional, el papel de las galerías de arte y la incidencia de la crítica de arte.

Palabras clave: Arte Latinoamericano, coleccionismo, exposiciones, XX, Estados Unidos.

\begin{abstract}
This text considers the presence of Latin American art in the United States from 1920 to 1990 with the so called Latin American art market boom. Our goal is to present in a synthetic way different moments that marked the artistic links between Latin America and the United States, especially the presence, in this country, of artists from Latin America. We will analyze individual and collective exhibitions, public and private collecting, institutional action, the role of art galleries and the incidence of art criticism.
\end{abstract}

Keywords: Latin American Art. collecting. exhibitions. XX. United States.

\section{Introducción}

La presencia del arte latinoamericano en Estados Unidos a lo largo del siglo XX ha estado marcada por diversos factores, y entre ellos adquieren singular importancia los vinculados a determinados intereses políticos-culturales trazados de norte a sur. A lo largo de estas páginas analizaremos algunos de los mismos, estableciendo un relato en el que la geopolítica y la economía se erigieron en factores extraculturales que van a marcar el desarrollo y la presencia de artistas latinoamericanos en suelo norteamericano. 
El interés de Estados Unidos por Latinoamérica es de carácter cíclico. En la década de los 20 se establece un estrecho contacto con México, marcado fundamentalmente por la presencia de artistas de este país en aquel, y la circulación de algunos estadounidenses por tierras del vecino. Esta situación será fundamental para fortalecer espacios de diálogo en los que de manera paulatina irán aumentando su presencia creadores de otras naciones latinoamericanas, como veremos más adelante.

En la década de los 30, marcada por el declive económico y el avance de los totalitarismos europeos, Estados Unidos incidirá con mayor fuerza en la idea de la solidaridad hemisférica a través de la consolidación del plan panamericanista. Este decenio culminará con la Exposición de Nueva York de 1939, que se convertirá, como veremos, no solamente en punto de confluencia de varios artistas latinoamericanos prestigiados a nivel internacional, sino que también significará el afianzamiento del coleccionismo latino en Estados Unidos y una decidida acción por parte de este país hacia el continente a partir de entonces. Está claro que en ello residía también la necesidad de abrir nuevos mercados, ante el cerramiento de Europa a causa de la guerra.

A partir de 1945, si bien continúan los vínculos estadounidenses-latinoamericanos a través de acciones institucionales (exposiciones, adquisiciones, etc.) y privadas, se advierte un retraimiento de Estados Unidos en su interés por el arte latinoamericano. Una de las razones la marca la apuesta por sus propios artistas, y en especial el expresionismo abstracto, una de las puntas de lanza de lo que Serge Gilbaut sintetizaría de manera clarividente en el título de su libro De cómo Nueva York robó la idea de arte moderno (1990).

Desde los 60 en adelante, más allá de algunas intermitencias, la presencia del arte latinoamericano en Estados Unidos va a gozar de buena salud, manifestándose al principio de esa década como un componente dentro de las estrategias iniciadas para frenar el avance del comunismo. A finales del decenio se producirán algunas exposiciones y publicaciones tendentes a establecer lecturas abarcativas del arte latinoamericano, que sentarán en algún caso bases para acciones puntuales a partir de allí. A principios de los 70 se incorporará con fuerza, dentro de las acciones, la promoción del arte chicano; poco después, y enmarcado en el protagonismo creciente del llamado arte de género, se pondrá de moda la mexicana Frida Kahlo.

En los 80 y 90 el boom del arte latinoamericano se convertirá en una de las pautas de mercado más sobresalientes, a la que acompañará un amplio programa de exposiciones, investigaciones, publicaciones e incrementos de acervos de obras y documentales. Entre los cambios más notables estará el hecho creciente de la coparticipación en estos proyectos, de historiadores del arte, críticos y otros especialistas, tanto de Estados Unidos como de Latinoamérica que, al confrontar ideas, irán permitiendo el acercamiento de posturas. Para los latinoamericanos esto irá significando el declive de ciertas condescendencias, de las miradas exoticistas, de la estigmatización de sus prácticas artísticas bajo miradas impuestas desde los centros hegemónicos, aunque no ha remitido del todo esa suerte de ansiedad de algunos latinoamericanos de ser vistos por el mainstream, y de buscar la legitimación y el reconocimiento en el norte como factor casi obligado de validación de lo propio. Esta situación, con algunas derivaciones, mantendrá e incrementará su ritmo desde entonces a la actualidad.

Con el presente ensayo, en definitiva, es nuestro objetivo presentar de una manera sintética diferentes momentos que jalonaron los vínculos artísticos entre Latinoamérica y Estados Unidos, y en especial la presencia, en este país, de artistas de aquella región. Exposiciones individuales y colectivas, coleccionismo público y privado, acción institucional, el papel de las galerías de arte, la incidencia de la crítica en la erección de relatos, son todos factores que estructuran este texto. Para confeccionarlo, nos hemos valido de diferentes libros y 
catálogos, sin apuntar, como es lógico, a un producto exhaustivo, imposible desde todo punto de vista en este espacio. Decidimos, sobre una organización cronológica, establecer una periodización tentativa, agrupando informaciones y reflexiones dentro de cada una de las etapas instituidas; al hacerlo así, está en nuestro ánimo disponer un cierto orden interno del texto y no dejar sentado dogmatismo alguno, ya que constatamos que un tema como el tratado, caracterizado por una amplia multiplicidad de hechos, nombres y sucesos, es plausible de periodizarse de maneras muy diferentes, según los ángulos en que se acometa la tarea.

Hemos centrado nuestra atención, pues, en una selección de información que nos permitiera trazar algunas reflexiones que se convierten así en ejes conductores. En esta faena reconocemos nuestra deuda con algunos trabajos que nos han precedido, en especial uno que consideramos fundacional desde la historia del arte para este tema, el libro titulado El espíritu latinoamericano: arte y artistas en los Estados Unidos, 1920-1970, coordinado en 1988 por Luís R. Cancel en el marco del Museo de Artes del Bronx neoyorquino, que nos proporcionó ciertas pautas de análisis sobre las que discurrir, aunque aportando varios datos novedosos y otras miradas.

\section{Estados Unidos y Latinoamérica se encuentran. Predominio presencial de México (1920-1929)}

Si tuviéramos que poner una fecha de inicio a esta relación de ida y vuelta podríamos comenzar con los felices años veinte, aunque hay algunos precedentes interesantes pero dispersos, como la presencia en Nueva York de la artista brasileña Anita Malfatti, el guatemalteco Carlos Mérida o el mexicano Marius de Zayas (Saborit y otros, 2009, pp. 162-174) durante la segunda década del siglo. Pero sin duda serán los veinte cuando comience a vislumbrarse la llegada de un importante número de artistas latinoamericanos a Estados Unidos, siendo Nueva York uno de los principales destinos de esta gira americana (Quirarte, 1988, p. 14).

En 1920 arribó a dicha ciudad el uruguayo Joaquín Torres García, siendo uno de sus objetivos centrales el producir industrialmente sus juguetes articulados. Un año después, expondría algunos de sus cuadros en el Studio Club. Su presencia motivó que se comenzaran a coleccionar sus obras muy lentamente, y en esos años la señora Whitney adquirió un conjunto importante de las mismas, y Catherine Dreier hizo lo propio con otras que se encuentran en la Universidad de Yale (Perazzo, 1988, p. 109).

En forma paralela a estos tímidos inicios, en México encontramos una serie de experiencias que marcarán directa o indirectamente la presencia de los artistas de ese país en Estados Unidos. Así, en 1926, Diego Rivera inicia la publicación de la revista Mexican Folkways (Sandoval Pérez, 1998, p. 57) y ese mismo año se celebra la exposición en la Galería de Arte Moderno de México D. F., que estableció un patrón expositivo que se mantendría vigente en los años 30 y 40: junto a las obras de artistas mexicanos se incluía arte indígena, colonial y popular contemporáneo. Esta forma de exponer pasó a Estados Unidos y no fueron pocas las ocasiones en que el arte contemporáneo mexicano quedó eclipsado por el impacto visual de las obras prehispánicas y el arte popular de ese mismo país.

Entre noviembre de 1925 y febrero de 1926 se celebró la First Pan American Exhibition of oil paintings, en el Museo de Los Ángeles. En el texto del catálogo que acompaña la muestra se expresa que el interés de los organizadores era el de presentar un panorama lo más amplio posible de las peculiaridades y riqueza del continente americano, incluyendo Canadá y Estados Unidos (las obras de ambas naciones conformaron la mitad del conjunto) y toda Latinoamérica (la otra mitad) (AA. VV., 1925, s/p). Unas 500 pinturas conformaron la muestra, prevaleciendo las propuestas tradicionalistas sobre las 


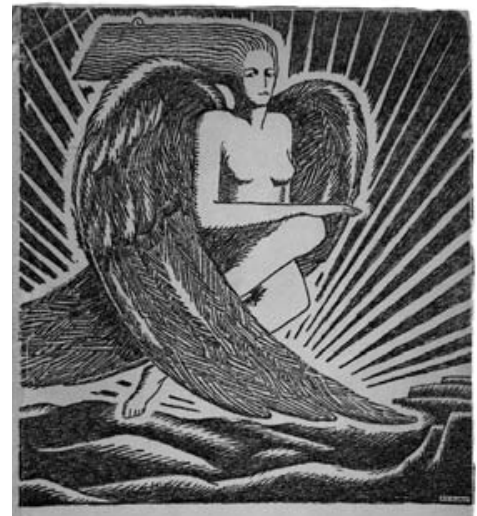

FIRST PAN AMERICAN EXHIBITION

OF OIL PAINTINGS

ASSEMBLED BY LOS ANGELES MUSEUM

Fig. 1. AA.VV. First Pan American exhibition of oil paintings. Los Ángeles: Los Angeles Museum, 1925. Colección MLR de avanzada. Buena parte de las obras fue reclutada en los propios países, aunque en varios casos se seleccionaron conjuntos de artistas latinoamericanos residentes en Francia y España. Perú y México fueron los países latinoamericanos más representados, de una manera ecléctica en cuanto a nombres y generaciones, con envíos en los que temáticas indígenas son mayoritarias, mezcladas con otros asuntos. (Fig.1)

México siguió manteniendo la delantera en este escenario. En 1927, la Weyhe Gallery, a cargo de Carl Zigrosser, mostró por primera vez obras de Diego Rivera a la par de editarse algunas litografías. El New York Evening Post, refiriéndose a la exposición, declaró que "conduce a la conclusión de que una peregrinación a México debería ser parte de la educación artística". Al año siguiente se producirá como hecho sobresaliente una exposición colectiva de arte mexicano en el Art Center de New York, fundado por los Rockefeller, con la participación de Diego Rivera, entre otros, y organizada por Frances Flynn Paine, representante del mismo.

En esa época el arte latinoamericano suscitaba ya gran interés en Estados Unidos. La proximidad física de México y los programas artísticos patrocinados por el Gobierno llamaron la atención. El Carnegie Institute emprendió expediciones arqueológicas a México y Guatemala. La mayoría de las colecciones de arte precolombino de los museos norteamericanos se conformaron en esa época, aprovechando la falta de una regulación legislativa sobre el patrimonio arqueológico.

\section{Entre el crack de la bolsa y la Exposición Internacional de Nueva York (1929-1939)}

El año 1929 quedó marcado por el llamado jueves negro, el 24 de octubre, en que comenzó el desplome de la bolsa de Nueva York, dando inicio a la Gran Depresión, de alcance internacional. Determinó el abrupto fin de los felices años 20, y el inicio de una era de incertidumbre que desembocaría en hechos como la Guerra Civil Española, primero, y luego la Segunda Guerra Mundial. Fue 1929 el año en que Sevilla celebró su recordada Exposición Iberoamericana, acción culminante de acercamiento entre España y sus antiguas colonias, ahora naciones soberanas, proceso iniciado tras la pérdida de Cuba, Puerto Rico y Filipinas, en 1898.

En la década que va desde este evento al de Nueva York en 1939, otro escenario de confluencia masiva de países latinoamericanos, con prestigiados pabellones y la participación activa de numerosos artistas, la presencia de Latinoamérica en Estados Unidos mantendrá su consolidación, acompañada de un creciente interés geopolítico. Este se materializará en la celebración de numerosas exposiciones de artistas latinoamericanos. Será también notable la labor llevada a cabo por el Museum of Modern Art (MOMA), institución que celebró en 1931 una exposición de Diego Rivera ${ }^{1}$ y en 1933 la muestra American sources of modern art (Gutiérrez Viñuales, 2013, p. 95) en la que coexistieron

1 La celebración de esta exposición fue decisiva en la consolidación de la obra de Diego Rivera; baste recordar que solamente antes Henri Matisse había contado con una monográfica en el museo. 
arte prehispánico y obras de artistas mexicanos y estadounidenses con reminiscencias precolombinas. (Fig. 2).

El arte contemporáneo mexicano, y en particular el muralismo, alcanzaron una marcada popularidad en el país. Rivera, Orozco y Siqueiros fueron a trabajar allí. Su arte sirvió de estímulo para que una generación de jóvenes pintores americanos asociados a la Work Progress Administration (WPA) aliviara sus dificultades económicas durante la Gran Depresión, además de alentar Estados Unidos desde entonces, y hasta entrados los años 40, un programa institucional de apoyo a los proyectos muralísticos de grandes similitudes con el mexicano, que en su concepción encerraba caracteres épicos y publicitarios, muy útiles como reclamo ideológico e, inclusive, comercial.

Las exposiciones de arte mexicano se multiplicaban dentro del país; Nueva York, Los Ángeles, Detroit, Boston, Filadelfia, entre otras ciudades,

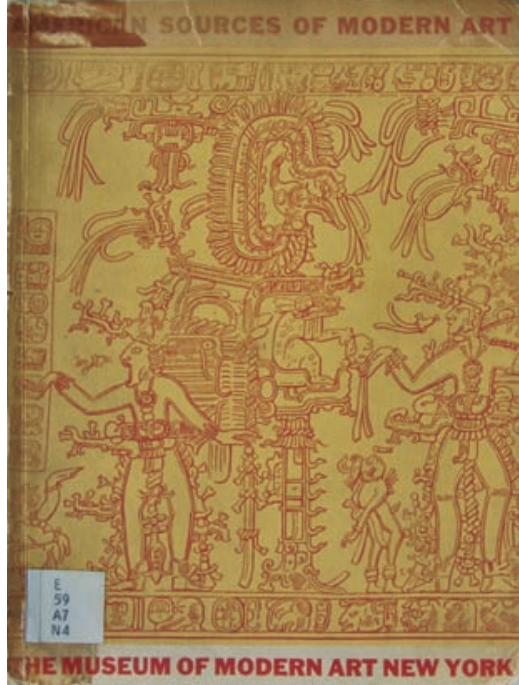

Fig. 2. Cahill, Holger. American sources of Modern Art. New York: the Museum of Modern Art, 1933. Colección MLR serían centros irradiadores al respecto. En este aspecto, destacaron una muestra de Diego Rivera, en Detroit (1931) y otra de Carlos Mérida, en Los Ángeles (1933). No obstante, en Nueva York la acción se mantenía de una manera continuada. En 1936 se celebró allí el I Congreso de Artistas Americanos con la presencia de Siqueiros, Orozco y Rufino Tamayo, que regresa a la ciudad desde México, donde es nombrado delegado mexicano al Congreso de Arte (Cockcroft, 1988, p. 189). En 1938 expone por primera vez Frida Kahlo, en la Galería Julián Levy, avalada por Andre Breton. Pero sin duda será 1939 año clave en este relato, al celebrarse en Nueva York la Exposición Internacional, siendo uno de sus highlights la exhibición del Guernica de Picasso, con varias itinerancias posteriores y que tanta influencia tendría a partir de entonces en la praxis de renombrados artistas latinoamericanos, como el brasileño Cándido Portinari o el mexicano Rufino Tamayo (Magalhães, 1999, p. 55).

En el evento neoyorquino confluyen numerosos artistas de la modernidad latinoamericana, en su mayor parte contratados por sus países de origen para hacer obras en los pabellones respectivos. Entre estos, los citados Tamayo y Portinari, como asimismo los argentinos Alfredo Guido y Lino Enea Spilimbergo, entre muchos otros. También en ese año llega a la ciudad el chileno Roberto Matta y su automatismo influirá en artistas norteamericanos, como Gorky, Pollock y Motherwell. El cubano Wifredo Lam realiza una exposición conjunta con Picasso en la Galería Perls. Entre 1939 y 1940 se celebró también otra exposición de carácter universal, la del Golden Gate en San Francisco, en cuyo marco se dedicó una exposición al arte mexicano moderno.

Visto en perspectiva, el evento neoyorquino de 1939, coincidente con el estallido de la Segunda Guerra Mundial, aparece como punto álgido en el proceso de acercamiento artístico entre Estados Unidos y Latinoamérica, en el que, además de aspectos citados, como la sucesión de exposiciones a lo largo y ancho de la geografía norteamericana, así como de los programas muralísticos de raíz mexicana, se consolidará sin prisa, pero sin pausa, otro aspecto esencial, como era el del coleccionismo. En efecto, entre 1935 y 1940, Abby Rockefeller donó al MOMA su colección de dibujos y estampas de Rivera y la obra El metro, de Orozco, lo que posibilitó la creación de una sección dedicada al arte latinoamericano. 
El mismo museo adquiriría en 1937 Eco de un grito, de Siqueiros, y El Nuevo Club Atlético de Chicago, del argentino Antonio Berni; al año siguiente, la obra Café, de Portinari. Como puede apreciarse, todos ellos con un transfondo social y/o político (Cockcroft, 1988, p. 192).

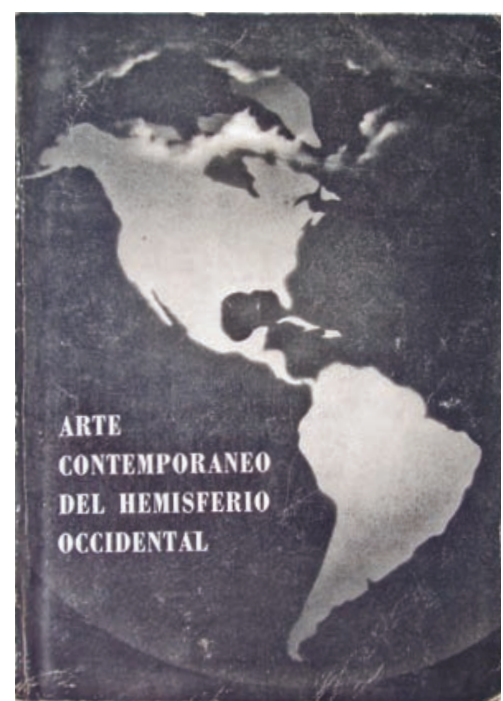

Fig. 3. Arte contemporáneo del Hemisferio Occidental. New York: International Business Machines Corporation, 1941. Colección MLR
Los años de la guerra. Una etapa de alta intensidad en el vínculo (1939-1945)

En la década de los cuarenta se acrecienta el interés por los artistas latinoamericanos en Estados Unidos, en parte motivado por la Segunda Guerra Mundial, que impide una presencia continuada del arte europeo ante las dificultades que supone organizar exposiciones con museos y coleccionistas del continente en guerra.

Entre 1940 y 1945, el MOMA sigue teniendo un papel bastante activo y se celebran varias exposiciones de arte latinoamericano, la mayor parte de ellas acompañada con la edición de libros-catálogo. A su vez, el museo organizó diecinueve muestras de pintura contemporánea norteamericana que fueron enviadas a distintos países latinoamericanos. Entre las exposiciones llevadas a cabo en el MOMA destacamos la de Veinte siglos de arte mexicano, en 1940, en la que se exhibe la obra Las dos fridas, de Frida Kahlo, y una individual dedicada a Cándido Portinari. En 1942 fue el turno para Brazil Builds 1652-1942, coordinada por Philip L. Goodwin, además de patrocinar el MOMA el Concurso de Diseño para las 21 Repúblicas Americanas y el Concurso de carteles del Hemisferio Unido, mientras que el Fondo Interamericano proporciona dinero al museo para la compra de 195 obras (Cockcroft, 1988, p. 194). En 1943 es el turno de la exposición The LatinAmerican Collection of the Museum of Modern Art. Ese mismo año el museo adquiere La jungla, de Wifredo Lam, que había realizado una exposición en la Galería Pierre Mattise, aunque dicho artista habría de estar ausente en la importante muestra Modern Cuban Painters, celebrada en el MOMA en 1944. (Fig. 3)

Junto al papel del MOMA como impulsor del arte latinoamericano, es importante destacar la labor llevada a cabo estos años por la OEA, Organización de Estados Americanos, que va a realizar entre 1941 y 1947 exposiciones de la boliviana Marina Núñez del Prado, del uruguayo Pedro Figari, del brasileño Cándido Portinari, del argentino Emilio Pettoruti y del guatemalteco Carlos Mérida. En estos años también comienzan a jugar un importante papel las publicaciones de catálogos y textos por parte de museos, universidades e instituciones culturales del país.

Además de esta intensa actividad, se siguen celebrando otras exposiciones, como la ya citada del Golden Gate, en San Francisco, con obras de Frida Kahlo, en 1940, o la de Roberto Matta, en Nueva York, organizada por Julien Levy; la exposición Modern mexican painters, en el Institute of Modern Art de Boston, en 1941; la Chilean contemporary art en el Toledo Museum of Art, en Ohio, en ese mismo año, o la primera muestra de Pettoruti en el Museo de Arte de San Francisco, en 1942.

\section{Estados Unidos se centra en su producción artística. Lo latinoamericano sujeto a la} acción de instituciones puntuales (1945-1962)

A partir de la década de los cincuenta, se advierte una cierta merma en el interés demostrado en Estados Unidos por los artistas latinoamericanos y una suerte de concentración 
de las actividades por parte de instituciones puntuales. Esta disminución se debe en parte al avance de jóvenes pintores del expresionismo abstracto, como Jackson Pollock, en lo que aparece como una operación estratégica de Estados Unidos por legitimarse como centro hegemónico del arte occidental. En este aspecto, queda como algo casi anecdótico el que Pollock hubiera reconocido la influencia de artistas mexicanos tanto en su creación plástica como en lo tocante a los formatos. Hay que destacar en este contexto la influencia de Siqueiros como precursor en el uso del dripping, que después popularizaría Pollock. En estos años muchos artistas latinoamericanos vuelven sus ojos nuevamente a Europa, sobre todo a París, provocando en algunos casos la consolidación de vías artísticas que se convertirán en centrales dentro del relato hegemónico de la historia del arte, como lo será la del arte cinético, en donde los venezolanos Jesús Rafael Soto y Carlos Cruz Díez, o el argentino Julio Le Parc, entre otros, alcanzarán una consagración internacional seguramente impensable de haberse quedado en sus países de origen, aprovechando espacios como el Salón des Realités Nouvelles o la Galería Denise René.

A pesar del cierto desinterés en Estados Unidos por lo latinoamericano, la OEA seguirá organizando exposiciones de artistas latinoamericanos, como las de Joaquín Torres-García (1950), Carlos Mérida (1952), Rufino Tamayo (1952), Fernando de Szyszlo (1953), el paisaje en Brasil y la obra de Roberto Burle Marx (1954), Roberto Matta (1955), Jorge Larco (1955), Oswaldo Guayasamín (1955), esculturas de Edgar Negret (1956), el fotógrafo mexicano Nacho López (1956), Fernando Botero (1957), Raquel Forner (1957) y Carlos Páez Vilaró (1958) (Perazzo, 1988, p. 116).

Por su parte, el MOMA, aunque más tímidamente, mantiene sus apuestas adquisitivas: en 1954 incorpora a su acervo una obra del colombiano Eduardo Ramírez Villamizar titulada Negro y blanco, y en 1957 organiza una muestra retrospectiva de Roberto Matta, que no gustó al artista chileno pues se lo vinculó solo con su componente surrealista europeo, olvidando sus obras posteriores.

La década de los cincuenta está marcada también por los premios y becas otorgados por la Fundación Guggenheim. En 1956, el argentino Pettoruti gana el Premio Continental Guggenheim con la obra Crepúsculo en el mar, y en ese mismo año tanto el colombiano Alejandro Obregón, con Velada o el velorio, como el brasileño Cándido Portinari, con Mujeres llorando, recibieron el Premio Nacional Guggenheim. Dos años después, Ramírez Villamizar obtiene la beca Guggenheim. A pesar de estos premios y reconocimientos, al inaugurarse en 1959, el Museo Guggenheim solo contaba con una obra de Wifredo Lam donada al museo por Joseph Cantor, coleccionista de arte cubano.

Al margen de Nueva York, Houston empieza a despuntar como ciudad interesada en promocionar el arte latinoamericano y en 1956 el Museo de Bellas Artes ${ }^{2}$ organiza la Gulf-Caribbean Art exhibition (Gómez Sicre, 1956, p. 47). En ese mismo año, el Institute of Contemporary Art en Boston organiza una exposición retrospectiva del venezolano Armando Reverón, entidad que albergaría un lustro después la muestra Latin-America: New Departures, con obras de Edgar Negret, Eduardo Ramírez Villamizar, Manube Mabe, Fernando de Szyszlo, Alejandro Obregón, Alejandro Otero, Ricardo Martínez y Armando Morales (Perazzo, 1988, p. 121.).

La Unión Panamericana también comienza a valorar el trabajo de estos creadores. En 1954 organiza la exposición del mexicano José Luis Cuevas, al que presenta como heredero de Orozco. Entre 1956 y 1973 se publican 23 números del Boletín de Artes Visuales, además

2 Se trata del quinto museo más grande de Estados Unidos, que alberga un centro de investigación dedicado al arte latinoamericano y latino-estadounidense, y en donde se da a ambos un tratamiento similar al de las obras de artistas estadounidenses consagrados, europeos y asiáticos. 


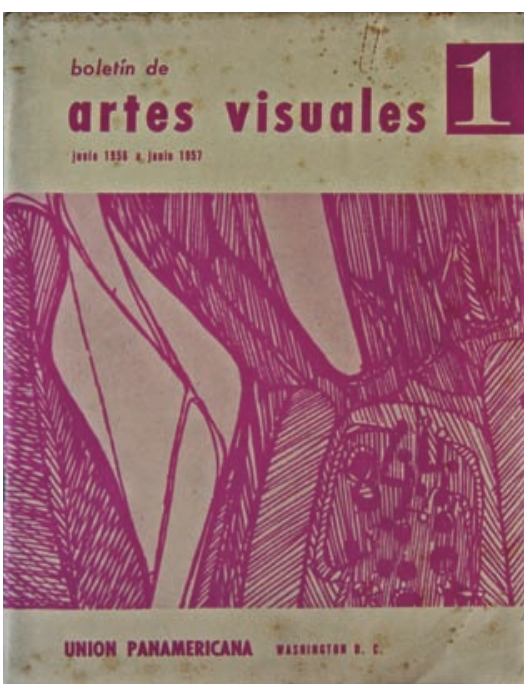

Fig. 4. Boletín de Artes Visuales. Washington: Unión Panamericana, 1956-1957. Colección MLR de una serie de monografías sobre algunos de los países latinoamericanos, fuentes excepcionales, sobre todo el Boletín, de las exposiciones y otras actividades artísticas realizadas a lo largo y ancho del continente. (Fig. 4).

Junto con las distintas exposiciones celebradas, surgen galerías comerciales que van gradualmente exponiendo arte latinoamericano. Destacamos en Nueva York la Galería Sudamericana, dirigida por Armando Zegrí, y la Galería Roland, de Aenlle, ambas dedicadas exclusivamente al arte latinoamericano, o la Galería David Herbert, abierta en 1959 y especializada en esculturas, que comercializó obras del colombiano Negret. En Washington destaca la Galería Gres, que en 1957 inauguró una exposición de Negret y Jack Youngerman. En Detroit destacamos la Galería 4 y la Galería Main Street; en todas ellas era habitual encontrar muestras de artistas latinos.

\section{Nuevas políticas culturales y acercamientos con razones geopolíticas como marco (1962-1970)}

Coincidiendo con los sesenta y la Guerra Fría hay un nuevo interés por los proyectos culturales como forma de acercamiento de Estados Unidos al resto del continente americano. La crisis de los misiles en Cuba, en 1962, propició esa proximidad para intentar frenar el avance del comunismo. Una vez más son cuestiones de geopolítica las que van a marcar, en parte, la presencia del arte latinoamericano en Estados Unidos.

En esta década siguen siendo el MOMA y la OEA las dos instituciones que más van a apostar por los creadores latinoamericanos. El museo va a adquirir varias obras, entre ellas la de la artista brasileña Lygia Clark, el colombiano Fernando Botero y un Proyecto para un mural horizontal, de su compatriota Ramírez Villamizar. También dedica en 1965 una exposición al arte cinético internacional, en la que incluyó la obra de siete artistas latinoamericanos, pero sin contar entre ellos con Jesús Rafael Soto y Alejandro Otero.

Por su parte, la OEA sigue con su política de organización de exposiciones, destacando las de Joaquín Torres García y Omar Rayo, ambas en 1961, y la primera exposición individual del ecuatoriano Enrique Tábara en Estados Unidos, en la Unión Panamericana de Washington en 1964. En estos años comienzan a proliferar las exposiciones en galerías privadas y al margen de las instituciones oficiales, lo que reafirma el interés de los coleccionistas por el arte latinoamericano. A propósito, podemos señalar la exposición individual de Lygia Clark en la Galería Louis Alexander de Nueva York, en 1963; la muestra individual de Soto titulada Vibrations by Soto, en Galería Kootz, en 1965, y la exposición individual de Antonio Berni en la Galería Huntington Hartford de Nueva York, en $1966^{3}$.

En la década de los sesenta destaca, entre otras, la Galería Bonino, con sedes en Buenos Aires, Londres, Río de Janeiro y Nueva York. Presentó lo mejor del arte argentino, desde la abstracción hasta la nueva figuración. Las galerías comerciales que se dedicaban

3 Recordemos que en 1962 Berni había ganado el premio de artes gráficas en la Bienal de Venecia con la serie de Juanito Laguna y que en 1963 se habían celebrado sendas exposiciones suyas en el Museo de Arte Moderno de Miami y en el Museo de Trenton en Nueva Jersey. 
exclusivamente al arte latinoamericano tuvieron poca duración y muchas desaparecieron. Otras se mantuvieron al incluir a artistas estadounidenses y mantener solo a los latinoamericanos establecidos (en muchos casos temporalmente) en Estados Unidos, como Matta, Marisol, Botero y Tamayo. En 1966 se celebró en el Guggenheim de Nueva York la exposición The Emergent Decade: Latin American Painters and Painting in the 1960's, donde se analizó el arte contemporáneo de varias naciones comprendidas entre México y el cono sur. Sufragada en parte por la Fundación Neumann de Caracas, en el catálogo, de gran interés documental, se incluyeron textos de críticos latinoamericanos, algo que no era muy habitual, pues siempre eran especialistas estadounidenses los que escribían los capítulos en los libros catálogos que acompañaban a las exposiciones.

Ese mismo año será de notoria importancia para el tema que nos ocupa la exposición Art of Latin American since Independence, organizada bajo la curaduría de Stanton L. Catlin, en la Galería de Arte de la Universidad de Yale y el Museo de Arte de la Universidad de Texas, en la que se intentaba estudiar con rigor la historia del arte contemporáneo latinoamericano desde principios del siglo XIX. (Fig. 5)

\section{Tránsitos hacia el boom del arte latinoamericano (1970-2000)}

La década de los setenta supone algunas alteraciones en el auge de los intereses expositivos, entrando en el panorama cultural el arte chicano que alcanzaría gran presencia en el decenio siguiente. Junto a estos creadores también surge el interés por visibilizar a otros colectivos, como ocurrió en 1976, al celebrarse en Los Ángeles la exposición titulada Women artists, 1550-1950, donde se incluyeron algunas obras de Frida

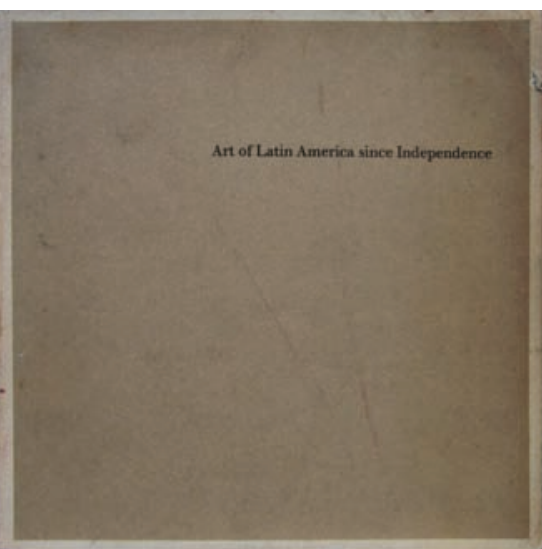

Fig. 5. Catlin, Stanton L. y Grieder, Terence. Art of Latin American since Independence. New York: The Yale University Art Gallery and the University of Texas Art Museum, 1966. Colección MLR

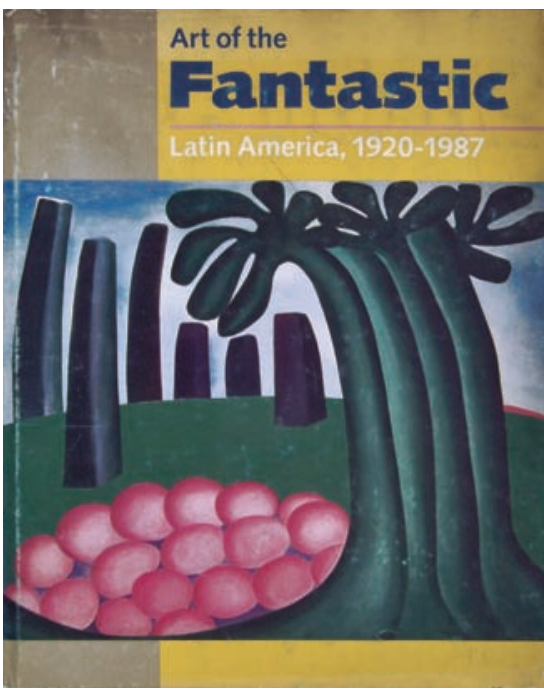

Fig. 6. Day, Holliday T. y Sturges, Hollister. Art of the fantastic. Latin American, 1920-1987. Indianapolis: Indianapolis Museum of Art, 1987. Colección MLR

Kahlo, muestra que luego recorrería varias ciudades americanas y marcó el inicio de la fridamanía.

La década de los ochenta se caracteriza por el llamado boom del arte latinoamericano ${ }^{4}$, que se materializa en el número de subastas realizadas en Estados Unidos y en la celebración de importantes exposiciones, donde la figura de Frida Kahlo adquiere un gran protagonismo. A pesar de este boom, se organizan algunas muestras de carácter internacional que contradicen el supuesto interés por lo latinoamericano; es el caso de la celebrada en 1985

4 El boom latinoamericano de los ochenta y noventa en el mercado se caracterizó en buena medida por el hecho de que quienes compraban eran coleccionistas latinoamericanos y los que vendían eran, en muchos casos, coleccionistas estadounidenses. 


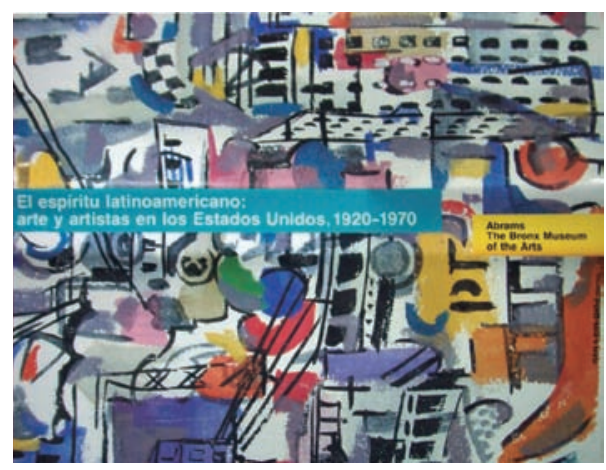

Fig. 7. Cancel, Luís y otros. El espíritu latinoamericano: arte y artistas en los Estados Unidos, 1920-1970. Nueva York: El Museo de Artes del Bronx, 1988. Colección MLR

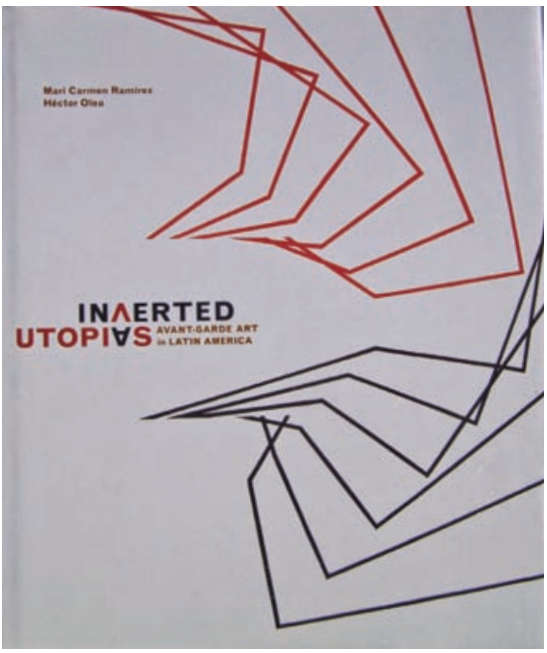

Fig.8. Rámirez, Ma . Carmen y otros. Inverted Utopias: Avant-Garde in Latin America. Nueva York: Yale University Press, 2001. Colección MLR en el MOMA: Contrasts of Form: Geometric Abstract Art, 1910-1980, donde no hay ninguna presencia de artistas latinoamericanos, ni siquiera el uruguayo Torres García. La muestra titulada Art of the fantastic. Latin American, 1920-1987, celebrada en 1987 en el Indianapolis Museum of Art, será muy criticada porque vinculaba a todos los artistas latinoamericanos con el surrealismo, con ese afán de estereotiparlos. Como se aprecia, la negación de lo latinoamericano en el discurso hegemónico universal y la clasificación congelada muestra una actitud condescendiente y equívoca. (Fig. 6).

También de 1987 data la muestra Latin American artists in New York since 1970, celebrada en el College of Fine Arts, de la Universidad de Texas en Austin, donde se presentó un importante número de artistas latinoamericanos que habían tenido un papel destacado dentro de la escena artística neoyorquina. $\mathrm{Al}$ año siguiente, la muestra El espíritu latinoamericano: arte y artistas en los Estados Unidos, 1920-1970, organizado por el Museo de Arte del Bronx, se erige en uno de los proyectos más serios y completos de los que se realizaron en Estados Unidos en nuestro periodo de estudio, tal y como lo comentamos en la introducción. (Fig. 7).

La cita a la Universidad de Texas en Austin no es una referencia menor; hay que recordar que desde la década de los cincuenta y sesenta esta institución desarrolló un amplio programa de estudios latinoamericanos con exposiciones de arte que se concretaron con la Colección de Siglo Veinte

de Latinoamérica, dentro de la Galería de Arte Archer M. Huntington de dicha entidad, que se convirtió en una de las más completas de su índole en Estados Unidos.

El auténtico boom se da a partir de la década de los noventa, cuando proliferan exposiciones de relevancia, como La mujer en México, que se celebró en Nueva York, ciudad de México y Monterrey, en 1990; la exposición de Artistas Latinoamericanos del Siglo XX celebrada en Sevilla, Colonia, París y el MOMA de Nueva York, entre 1992 y 1993, y la inaugurada en 1994 en el Museo de Arte de Milwaukee, bajo el título Latin American Women artists 1915-1995.

Podríamos terminar esta apretada síntesis de momentos y acontecimientos con la referencia a la recordada exposición Inverted Utopias: Avant-Garde in Latin America, ya de 2011, que anticipa un periodo de alta densidad de muestras y actividades museísticas vinculadas al arte latinoamericano en los Estados Unidos, el cual llega hasta la actualidad, y del que bien podríamos citar como una de sus últimas realidades destacadas el ambicioso proyecto de exposiciones Pacific Standard Time: LA/LA, que se está llevando a cabo entre 2017 y 2018 con el concurso de varias instituciones del sur de California, y que explora conexiones entre Latinoamérica y Los Ángeles (Fig. 8). 


\section{Referencias bibliográficas}

AA. VV. (1925). First Pan American exhibition of oil paintings. Los Ángeles: Los Angeles Museum.

Cancel, L. y otros (1988). El espíritu latinoamericano: arte y artistas en los Estados Unidos, 1920-1970. Nueva York: El Museo de Artes del Bronx.

Cockcroft, E. (1988). Los Estados Unidos y el arte latinoamericano de compromiso social. En El espíritu latinoamericano: arte y artistas en los Estados Unidos, 1920-1970. (ed. Luís Cancel). Nueva York: El Museo de Artes del Bronx.

Gómez Sicre, J. y otros (1956). Gulf-Caribbean art exhibition. Houston: Museum of Fine Arts.

Gutiérrez Viñuales, R. (2013). "Recuperación prehispánica en la contemporaneidad. Tradición, vanguardia y fortuna crítica”. En Revista de Historiografía. (19 X (2/2013): 88-100).

Magalhäes, F. y otros (1999). Picasso, cubismo e América Latina. Porto Alegre: Fundação Bienal de Artes Visuais do Mercosul.
Perazzo, N. (1988). El constructivismo y la abstracción geométrica En El espíritu latinoamericano: arte y artistas en los Estados Unidos, 1920-1970. (ed. Luís Cancel). Nueva York: El Museo de Artes del Bronx.

Quirarte, J. (1988). Artistas mexicanos y méxicoamericanos, 1920-1970. En El espíritu latinoamericano: arte y artistas en los Estados Unidos, 19201970. (ed. Luís Cancel). Nueva York: El Museo de Artes del Bronx.

Saborit, A. y otros (2009). Marius De Zayas. Un Destierro Moderno. México.

Sandoval Pérez, M. (1998). Arte y folklore en mexican folkways. México: UNAM. Instituto de Investigaciones Estéticas.

Sims, L. S. (1988). El dadá en Nueva York y el surrealismo en el Nuevo Mundo. En El espíritu latinoamericano: arte y artistas en los Estados Unidos, 1920-1970. (ed. Luís Cancel). Nueva York: El Museo de Artes del Bronx. 